\title{
PAPER
}

1

Cite this: DOI: 10.1039/c3ta15405j
10

Received 27th December 2013 Accepted 7th February 2014

DOI: $10.1039 / c 3 t a 15405 j$

www.rsc.org/MaterialsA

\section{Chemically stable magnetic nanoparticles for metal adsorption and solid acid catalysis in aqueous media†}

\author{
T. Okada, ${ }^{* a}$ Y. Takeda, ${ }^{a}$ N. Watanabe, ${ }^{a}$ T. Haeiwa, $^{b}$ T. Sakai ${ }^{a}$ and S. Mishima ${ }^{a}$
}

We have developed a magnetically collectable, reusable adsorbent and a catalyst for concentrating heavy metal ions in acidic aqueous solutions and solid acid catalysis in aqueous media. Chemically stable, magnetic rattle-type core-shell particles, comprising metallic cobalt nanoparticles in hollow silica microspheres, were prepared by the sol-gel reaction of alkylsilyl trichlorides around water droplets in a water-in-oil emulsion. Sulfonic groups were immobilized on the external surface of the core-shell particles through silylation with 3-mercaptopropyl(trimethoxysilane) and subsequent oxidization of the thiol groups by nitric acid. The sulfonic groups acted as adsorption sites for $\mathrm{Zn}$ and $\mathrm{Pb}$ ions under acidic conditions and as catalytically active sites for the hydrolysis of ethyl acetate in aqueous media. The enclosed Co was not eroded during the regeneration of the adsorbent/catalyst by $1 \mathrm{M} \mathrm{HCl}$. The chemical stability arose from the dense non-porous shell, which prevents the passage of solvents.

\section{Introduction}

The functionalization of magnetic nanoparticles by hybridization has received much attention in many areas, such as industrial chemistry and biomedical engineering, for separation, transportation, and imaging by external magnetic fields. ${ }^{\mathbf{1 - 6}}$ Agents that are environmentally compatible with water and biological systems and agents that respond to stimuli such as heat $^{7,8}$ and light, ${ }^{9}$ have been used for functionalization. Ultrafine particles and fibers have recently been developed as adsorbents for the remediation of toxic metals from wastewater. ${ }^{10-13}$ Active sites for adsorption and catalysis have also been immobilized on magnetic nanoparticles to create adsorbents and catalysts that are magnetically separable from liquid media. This prevents clogging during filtration and recovery that is more energetically efficient and faster than centrifugation. Superparamagnetic properties are important for magnetic separation because they allow easy recovery and dispersion in response to external magnetic fields. ${ }^{14}$ It is necessary to prevent the nanoparticles agglomerating in order to maintain their nanomagnetic functionality. Thus, core-shell or A@B particles (A: core, B: shell) have been prepared using various synthetic

${ }^{a}$ Department of Chemistry and Material Engineering, Faculty of Engineering, Shinshu University, 4-17-1 Wakasato, Nagano 380-8553, Japan. E-mail: tomohiko@shinshu-u. ac.jp; Fax: +81-26-269-5424; Tel: +81-26-269-5414

${ }^{b}$ Department of Computer Science and Engineering, Faculty of Engineering, Shinshu University, 4-17-1 Wakasato, Nagano 380-8553, Japan precipitate from the $\mathrm{W} / \mathrm{O}$ emulsion containing $\mathrm{Co}\left(\mathrm{NO}_{3}\right)_{2}$, the calcination precipitate and that after annealing at $973 \mathrm{~K}$ in nitrogen, and the XPS survey spectrum of Co@SiO ${ }_{2}$-SPS. See DOI: 10.1039/c3ta15405j

strategies, including self-assembled monolayers, layer-by-layer deposition, and sol-gel reactions. ${ }^{6,15-17}$

Chemically stable magnetism, where the magnetic particles are protected from oxidation and dissolution, is a prerequisite for reusable adsorbents, catalysts, and biomedical agents. Therefore, the stability of the nanoparticles has been investigated in various atmospheres and liquids. ${ }^{18-27}$ There are several examples of magnetic nanoparticles in aqueous solutions. ${ }^{27-46}$ For example in A@B particles, A components of magnetite $\left(\mathrm{Fe}_{3} \mathrm{O}_{4}\right),{ }^{27-38}$ maghemite $\left(\gamma-\mathrm{Fe}_{2} \mathrm{O}_{3}\right)^{39-45}$ and $\mathrm{FePt},{ }^{46}$ and $\mathrm{B}$ components of organic polymers, ${ }^{31-33,42}$ amines, ${ }^{34}$ acids ${ }^{35,36,43}$ cyclodextrins, ${ }^{46}$ silica (organosilicas), ${ }^{27-30,38-40}$ titania $^{41}$ and titanosilicates ${ }^{44}$ have been reported. Using modified magnetic nanoparticles for heavy metal adsorption ${ }^{30,32,33,35,36,38,39,42,43}$ is problematic under acidic conditions, because methods for modification are limited. Silica is a useful shell substance, owing to its acid-tolerance ${ }^{26}$ as well as its varied structural and morphological forms. A dense silica shell, which prevents the passage of water, is necessary to protect the core magnetic compound. The thickness and density of the silica shell can be controlled by varying the amount of silica precursors and by tuning the polycondensation process, respectively, to provide chemically stable magnetic nanoparticles.

We have developed magnetically collectable and reusable functional particles for heavy-metal ion-concentration in acidic solution and solid acid catalysis in aqueous media. For this purpose, sulfonic groups, which are allowed to act as repeated cation exchange and acid-catalyzed reactions, were anchored covalently onto the external surface of magnetic rattle-type Co@silica core-shell particles with a dense silica shell. The synthetic approach of the magnetic core-shell particles was based on the deposition of a polyalkylsiloxane shell, which is 

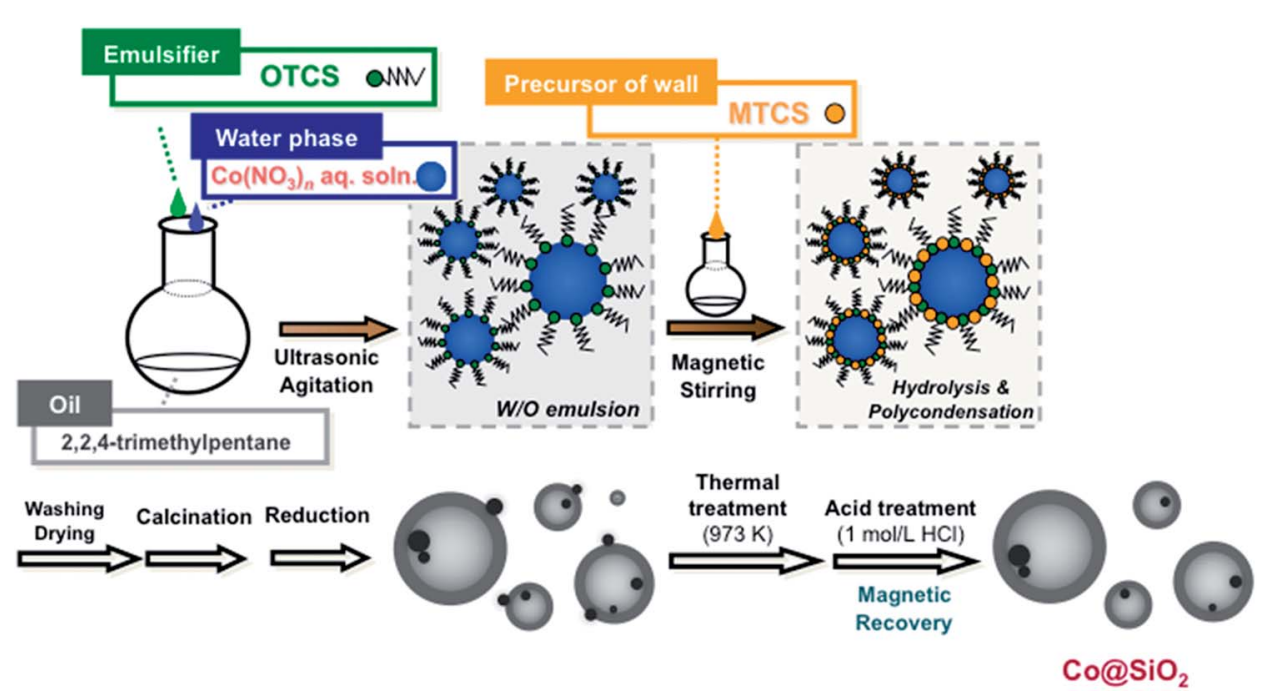

Scheme 1 Schematic drawing of the preparation of $\mathrm{CoOSiO}_{2}$ particles.

the precursor of the silica shell, on water droplets in a water-inoil (W/O) emulsion through the sol-gel reaction of octyl- and methyl-trichlorosilanes. ${ }^{47,48}$ The water droplets contained the cobalt nitrate starting material for the magnetic particles. The vaporization of the water in the resulting capsules, followed by calcination, reduction and annealing, resulted in metallic cobalt particles enclosed by a dense silica shell (Scheme 1). ${ }^{49,50}$ Because of the dense silica shell, the covalently attached sulfonic groups on the magnetic particles were successfully regenerated by $1 \mathrm{M} \mathrm{HCl}$ after they had adsorbed heavy metals ( $\mathrm{Zn}(\mathrm{II})$ and $\mathrm{Pb}(\mathrm{II})$ ) without eroding the enclosed Co particles. Moreover, the sulfonic groups acted as a catalytically active site in water for hydrolysis of ethyl acetate.

\section{Experimental}

\section{Chemicals and reagents}

Octyltrichlorosilane (OTCS) and methyltrichlorosilane (MTCS) were purchased from Aldrich Chemical Co., Ltd, and Shin-Etsu Chemical Co., Ltd, respectively. Cobalt(II) nitrate hexahydrates, isooctane (2,2,4-trimethylpentane), hexadecyltrimethylammonium bromide, 3-mercaptopropyl(trimethoxysilane) (MPS), and dry toluene were purchased from Wako Chemical Co., Ltd. These materials were used as received.

\section{Preparation of rattle-type Co particles encapsulated in a dense silica shell (Scheme 1)}

Rattle-type Co core and silica shell particles $\left(\mathrm{Co} @ \mathrm{SiO}_{2}\right)$ were prepared by using a previously reported procedure. ${ }^{50} \mathrm{~A}$ W/O emulsion was created by mixing water $(0.22 \mathrm{~mL})$, an aqueous solution of $\mathrm{Co}\left(\mathrm{NO}_{3}\right)_{2}\left(0.75 \mathrm{~mL}, 3.0 \mathrm{~mol} \mathrm{~kg}{ }^{-1}\right)$, and OTCS $(2.97 \mathrm{~g})$ in isooctane $(50 \mathrm{~mL})$ by ultrasonic agitation. After $5 \mathrm{~min}$ ultrasonic irradiation $(45 \mathrm{kHz}, 100 \mathrm{~W})$, the mixture was allowed to stand for $5 \mathrm{~min}$ at room temperature. The ultrasonic agitation was repeated three times. MTCS $(1.34 \mathrm{~g})$ in isooctane $(10 \mathrm{~mL})$ was poured into the $\mathrm{W} / \mathrm{O}$ emulsion under magnetic stirring. The mixture was stirred at room temperature for more than $3 \mathrm{~h}$ to form polymethylsiloxane shells around aqueous droplets. During the reaction, air saturated with water vapor $\left(0.1 \mathrm{~L} \mathrm{~min}^{-1}\right)$ was continuously supplied. After filtration, the product was washed with isooctane and then dried at $323 \mathrm{~K}$ for 1 day.

The dried product was heated at $393 \mathrm{~K}$ in air for 1 day, and then calcined at $873 \mathrm{~K}$ in an electronic furnace for $3 \mathrm{~h}$. The calcined solid was treated under a flow of $\mathrm{H}_{2}\left(5 \mathrm{~mL} \mathrm{~min}{ }^{-1}\right)$ at $773 \mathrm{~K}$ for $3 \mathrm{~h}$, and subsequently heated at $973 \mathrm{~K}$ for $3 \mathrm{~h}$ in a flow of $\mathrm{N}_{2}\left(10 \mathrm{~mL} \mathrm{~min}{ }^{-1}\right)$. The product was then washed with $1 \mathrm{M}$ $\mathrm{HCl}$. The acid-treated sample was recovered using neodymium magnets. $\$$ The recovered sample was thoroughly washed with water before further magnetic recovery to obtain $\mathrm{Co@SiO}_{2}$ particles. The amount of $\mathrm{Co}$ in the $\mathrm{Co@SiO}_{2}$ particles was estimated by inductively coupled plasma-atomic emission spectroscopy (ICP-AES) analysis after it was converted to aqueous form by alkali fusion. The amount of the Co leached during immersion of $\mathrm{Co}_{0} \mathrm{SiO}_{2}(20 \mathrm{mg})$ in an aqueous solution of $1 \mathrm{M} \mathrm{HCl}(4 \mathrm{~mL})$ for 7 days was also determined by ICP-AES. Before the experiment, the sample was dried at $323 \mathrm{~K}$ overnight.

\section{Immobilization of sulfonic groups on $\mathrm{Co@SiO}_{2}$}

Reactions of MPS with $\mathrm{Co@SiO}_{2}$ were carried out using a procedure based on the silylation of a layered alkali silicate. ${ }^{51}$ Before the silylation, $\mathrm{Co}^{\circ} \mathrm{SiO}_{2}(0.52 \mathrm{~g})$ was immersed in an aqueous $1 \mathrm{M} \mathrm{NaOH}$ solution $(200 \mathrm{~mL})$ for $12 \mathrm{~h}$ at room temperature. The alkali-treated particles were dispersed in a solution of hexadecyltrimethylammonium bromide $(1.3 \mathrm{~g})$ in water-ethanol $(1: 1 \mathrm{v} / \mathrm{v})$. The resulting solid was transferred into a solution of MPS $(0.4 \mathrm{~mL})$ in dry toluene $(80 \mathrm{~mL})$. The mixture was heated for $3 \mathrm{~h}$ at $333 \mathrm{~K}$ and then concentrated under reduced pressure at 333 $\mathrm{K}$ for $2 \mathrm{~h}$ to evaporate toluene. The product was washed with a

$\ddagger$ Magnetic recovery in our study has been performed as follows: neodymium magnets, whose surface magnetic field is $3.8 \mathrm{kOe}$, located at both sides of a glass bottle (outer diameter of $21 \mathrm{~mm}$ ). The magnetic field gradient from the center of the glass bottle to the magnet was $1.9 \times 10^{2} \mathrm{kOe} \mathrm{m}^{-1}$. 
mixture of $0.1 \mathrm{M} \mathrm{HCl}$ aqueous solution and ethanol $(1: 1 \mathrm{v} / \mathrm{v})$. The washed solid was allowed to react with aqueous $7 \mathrm{M} \mathrm{HNO}_{3}$ $(50 \mathrm{~mL})$ for $6 \mathrm{~h}$. After washing with water, the solid product was magnetically collected, $\$$ and the supernatant was decanted. The product was dried at $323 \mathrm{~K}$ in air.

The cation exchange capacity was determined by the reaction of $\mathrm{NaCl}$ with the protons of the trisilylpropylsulfonic groups. The sample was allowed to react with an aqueous 4 mass $\% \mathrm{NaCl}$ solution, and then the resulting solid was recovered with a magnet. $\$$ These steps were repeated to complete the exchange reactions. The supernatant was titrated with $\mathrm{NaOH}$ aqueous solution.

\section{Adsorption of transition metal ions}

The sample modified with sulfonic groups $(0.08 \mathrm{~g})$ was allowed to react with aqueous solutions containing transition metal ions $\left(20 \mathrm{~mL}, \mathrm{ZnCl}_{2}\right.$ or $\mathrm{Pb}\left(\mathrm{NO}_{3}\right)_{2}$, initial $\mathrm{pH}$ of 2.5 or 5.2$)$ in a Pyrex flask for $24 \mathrm{~h}$ at $298 \mathrm{~K}$ with reciprocal shaking. After the reactions, the adsorbent was recovered magnetically.t The initial concentrations of $\mathrm{ZnCl}_{2}$ or $\mathrm{Pb}\left(\mathrm{NO}_{3}\right)_{2}$ were 0.4 and $4 \mathrm{mM}$, which correspond to the cation exchange capacity and to 10 -fold the cation exchange capacity, respectively. Blank samples containing the aqueous solutions $(20 \mathrm{~mL})$, without adsorbents, were also prepared to estimate the adsorption of the metal ions in the Pyrex flask. The amount of metal ions adsorbed onto the sample was determined by ICP-AES analysis from the difference between the concentration of the metal ions in the supernatant and that of the blank sample. In order to verify the regeneration of the adsorbent, the sample was immersed in $1 \mathrm{M} \mathrm{HCl}$ aqueous solution with reciprocal shaking for $6 \mathrm{~h}$, followed by the above recycling adsorption experiment. The amount of Co ions leached during the adsorption and the regeneration was estimated by ICP-AES.

\section{Hydrolysis of ethyl acetate in aqueous solution}

Hydrolysis of ethyl acetate was conducted in a 2-necked Pyrex flask equipped with a refluxing condenser and a thermometer. The reaction of the sample modified with sulfonic groups $(0.1 \mathrm{~g})$ was carried out at $343 \mathrm{~K}$ for $2 \mathrm{~h}$ with stirring using an aqueous solution of ethyl acetate $(30 \mathrm{~mL}, 18 \mathrm{mmol}$ ethyl acetate). The amount of catalyst used in the first run was $2.0 \times 10^{-5} \mathrm{mmol}$. After the first run, the recycling reaction was performed. After the first run, the resulting aqueous suspension was transferred into a glass vial, and the catalyst was recovered magnetically: before the reaction mixture was decanted. The catalyst after the reaction was washed with aqueous 4 mass $\% \mathrm{NaCl}$ solution to estimate the cation exchange capacity. After washing with aqueous $1 \mathrm{M} \mathrm{HCl}$, the catalyst was immersed in a fresh ethyl acetate solution to perform the recycle reactions as described above. The reactant and products (ethanol and acetic acid) were commercial guaranteed reagents (Wako Pure Chemicals) and were used as received. All the solutions were prepared from Elix-UV pure water (Millipore). The products were analyzed with a gas chromatograph using a DB-WAX capillary column (Agilent J\&W).

\section{Instruments}

X-ray powder diffraction (XRD) patterns were obtained by using a Rigaku RINT 2200V/PC diffractometer (monochromatic $\mathrm{Cu} \mathrm{K} \alpha$ radiation), operated at $20 \mathrm{~mA}$ and $40 \mathrm{kV}$. Fourier transforminfrared (FT-IR) spectra were recorded using a JASCO FT/ IR-4200 spectrophotometer using the $\mathrm{KBr}$ pellet method. Scanning electron micrographs were obtained using a Hitachi S-4100 field-emission scanning electron microscope (SEM) at an accelerating voltage of $15 \mathrm{kV}$. The transmission electron micrographs with energy dispersive X-ray (EDX) mapping were obtained using a Hitachi High-Tech HD-2300A spherical aberration corrected scanning transmission electron microscope (STEM) equipped with an EDAX Genesis XM 4 EDX spectrometer (accelerating voltage of $200 \mathrm{kV}$ ). Nitrogen adsorptiondesorption isotherms at $77 \mathrm{~K}$ were obtained by using a BEL Japan BELSORP-mini instrument. Before the adsorption experiments, the samples were heat-treated at $473 \mathrm{~K}$ under reduced pressure. ICP-AES was performed using a HitachiHighTech SPS5510 spectrometer. Magnetization curves were obtained from a Toei Kogyo VSM-5S vibrating sample magnetometer (VSM). X-ray photoelectron spectroscopy (XPS) was performed using a JEOL JPS-9010MX photoelectron spectrometer ( $\mathrm{Mg} \mathrm{K} \alpha$ radiation, $1253.6 \mathrm{eV}$ ), operated at $20 \mathrm{~mA}$ and $10 \mathrm{kV}$.

\section{Results and discussion}

\section{Preparation of $\mathrm{Co@SiO}{ }_{2}$}

Ultrasonic agitation of a mixture of OTCS dissolved in an aqueous solution of 2,2,4-trimethylpentane and $\mathrm{Co}\left(\mathrm{NO}_{3}\right)_{2}$ formed a blue W/O emulsion. Addition of MTCS produced a light blue precipitate. When the dried precipitate was calcined at $873 \mathrm{~K}$, it turned blue-gray, indicating oxidation to cobalt oxide. The XRD pattern of the calcined sample (Fig. 1a) contains diffraction peaks corresponding to $\mathrm{Co}_{3} \mathrm{O}_{4}$. The FT-IR absorption bands of the polyalkylsiloxane alkyl groups $\left(\nu_{\mathrm{C}-\mathrm{H}}\right.$ at around $2900 \mathrm{~cm}^{-1}$ ) and the Si-C bond (at around $1300 \mathrm{~cm}^{-1}$ ) are weak, indicating that calcination turned most of the polyalkylsiloxane to silica (see ESI, Fig. S1 $\dagger$ ). The specific surface area derived from the BET-plot of the calcined sample $\mathrm{N}_{2}$ adsorption isotherm was $40 \mathrm{~m}^{2} \mathrm{~g}^{-1}$. The calcined sample consisted of spherical hollow particles of microporous silica encapsulating cobalt oxides.

Fig. 2a shows the SEM image of particles after they were reduced in $\mathrm{H}_{2}$ gas then annealed in $\mathrm{N}_{2}$ at $973 \mathrm{~K}$. Most of the particles were microspheres of various diameters reflected from the variation of the droplet size in the $\mathrm{W} / \mathrm{O}$ emulsion. The average particle size determined from the SEM observations was $0.26 \mu \mathrm{m}$ (inset of Fig. 2a). There was no IR absorption band from organic compounds for the annealed sample (Fig. S1c $\dagger$ ). The specific surface area was decreased by annealing from 40 to $20 \mathrm{~m}^{2} \mathrm{~g}^{-1}$, suggesting that the silica shell was partly transformed into a dense non-porous phase. In the XRD pattern of the reduced sample (Fig. 1b), $\mathrm{CoO}$ and metallic $\mathrm{Co}$ (fcc) diffraction peaks were observed, revealing that $\mathrm{Co}_{3} \mathrm{O}_{4}$ was reduced to metallic cobalt (partially reduced to divalent $\mathrm{Co}$ ). The hydrogen gas penetrated the porous silica shell during the 


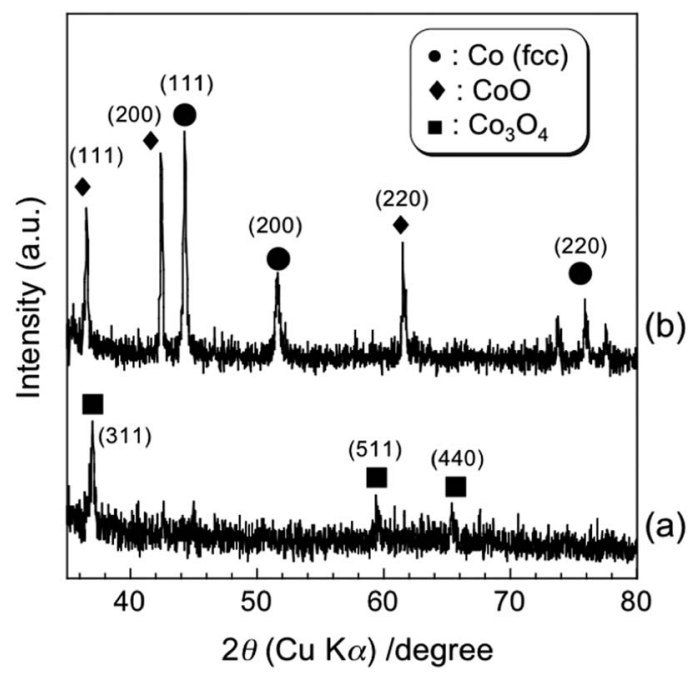

Fig. 1 XRD patterns of (a) the precipitate from the W/O emulsion containing $\mathrm{Co}\left(\mathrm{NO}_{3}\right)_{2}$ calcined at $873 \mathrm{~K}$ and (b) reduced (a) in $\mathrm{H}_{2}$ gas at $773 \mathrm{~K}$.

reduction at $673 \mathrm{~K}$. After heat treatment at $973 \mathrm{~K}$ in $\mathrm{N}_{2}$, the porous silica shell was transformed into dense non-porous silica, although the metallic Co remained unchanged.

The reduced sample of $\mathrm{Co} \mathrm{SiO}_{2}$ was agitated in $1 \mathrm{M}$ aqueous $\mathrm{HCl}$ and then collected using a magnet. Under our experimental conditions, it took no more than 1 min to gather the particles from the acidic solution. Fig. $2 \mathrm{~b}$ shows the shape of the $\mathrm{Co@SiO} \mathrm{Si}_{2}$ was maintained after agitation in $1 \mathrm{M} \mathrm{HCl}$ Although only a slight portion (less than $1 \%$ ) of larger particles $(>1 \mu \mathrm{m})$ was observed, most of the particles are below $1 \mu \mathrm{m}$. The average particle size of $\mathrm{Co@SiO}{ }_{2}$ was $0.25 \mu \mathrm{m}$ which was similar
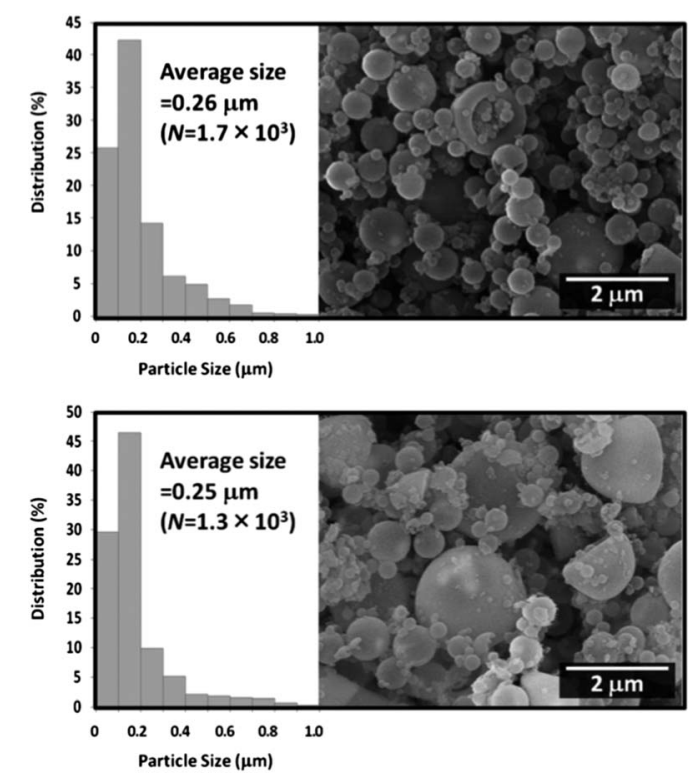

(b)

Fig. 2 SEM images of the particles and their particle size distributions (inset). (a) After heating in $\mathrm{N}_{2}$ at $973 \mathrm{~K}$. (b) After agitating the sample heat-treated at $973 \mathrm{~K}$ in $\left.1 \mathrm{M} \mathrm{HCl}(\mathrm{CoOSiO})_{2}\right)$.

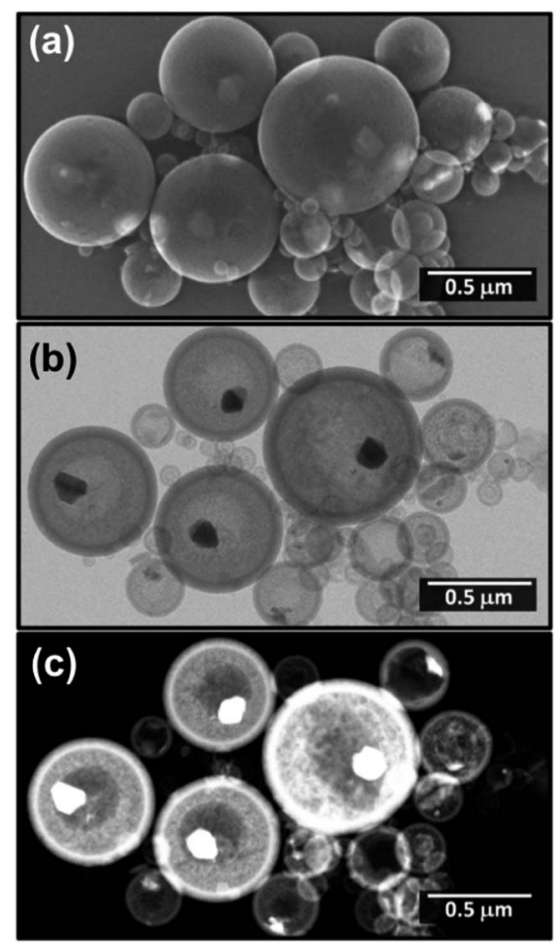

Fig. 3 (a) SEM image, (b) bright-field TEM image, and (c) STEM darkfield image of $\mathrm{CoCSiO}$.

to that of the reduced sample $(0.26 \mu \mathrm{m})$, and that the particle size was not altered by the acid treatment (inset of Fig. 2b).

Fig. 3a-c shows SEM, bright-field TEM, and STEM dark-field images of $\mathrm{Co@SiO}_{2}$. A rattle type core-shell structure was observed in the TEM image for most of the particles. The STEM dark-field image confirmed that the core and shell were composed of cobalt and silica, respectively, because the contrast of the core is brighter than that of the shell. The SEM image shows that the Co particles were not present on the silica surface. The majority of the Co agglomerated inside the hollow silica spheres rather than being dispersed as nanoparticles. The amount of Co encapsulated in the $\mathrm{Co@SiO}_{2}$ particles was 7.8 mass\%.

\section{Stability of encapsulated magnetic Co particles under acidic conditions}

Fig. 4 shows the response of the $\mathrm{Co@SiO}$ particles to a magnet after immersion in $1 \mathrm{M} \mathrm{HCl}$. The particles in the sample bottle were attracted to the magnet, confirming that the $\mathrm{Co@SiO}_{2}$ nanoparticles were acid-tolerant magnetic particles. The color change of the $\mathrm{pH}$ indicator paper from yellow to red in acidic solution is also shown in this figure. The magnetism persisted, even after the nanoparticles were immersed in $\mathrm{HCl}$ for 1 year. The VSM results showed that a saturation magnetization of $4.0 \mathrm{emu}^{-1}$ (ref. 50) did not decrease substantially during the period of 1 week in $1 \mathrm{M} \mathrm{HCl}$ aqueous solution, showing that the $\mathrm{Co@SiO}{ }_{2}$ particles were acid tolerant.

Because metallic cobalt and magnetite are readily dissolved in mineral acids, ${ }^{52}$ the stability tests verified that the magnetic particles can be shielded from acidic solution by the dense 


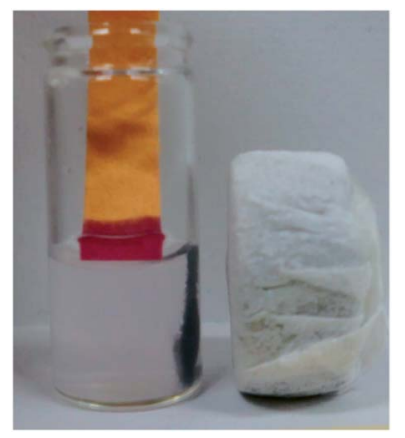

Fig. 4 The behaviour of $\mathrm{Co} \mathrm{aSiO}_{2}$ exposed to a magnet (right-side) after immersion in $1 \mathrm{M} \mathrm{HCl}$. Particles in the sample bottle were attracted to the magnet. The photograph also shows that the color of the $\mathrm{pH}$ indicator paper turned from yellow to red in the acid solution.

silica shell. Aslam et al. ${ }^{25}$ fabricated $\mathrm{Co} @ \mathrm{SiO}_{2}$ nanoparticles from tetramethylorthosilicate and $\mathrm{CoCl}_{2}$, and found that the Co-core of the particle dissolved completely in $1 \mathrm{M} \mathrm{HCl}$ within $12 \mathrm{~h}$. Their results suggest that the acid solution passed through the silica shell and the Co-core was readily dissolved in the aqueous $\mathrm{HCl}$. In our system, the magnetism was lost in $1 \mathrm{M} \mathrm{HCl}$ for both samples that were not heat-treated in $\mathrm{N}_{2}$ at $973 \mathrm{~K}$. In contrast, Co@carbon nanoparticles are stable in $\mathrm{HNO}_{3}(53 \mathrm{wt} \%)$ for 2 months. ${ }^{22}$ This indicates that the majority of the Co particles was protected by dense shells. Therefore, the acidtolerant properties of the $\mathrm{Co} @ \mathrm{SiO}_{2}$ nanoparticles were attributed to the formation of a dense non-porous shell.

\section{Immobilization of sulfonic groups on $\mathrm{Co@SiO}$}

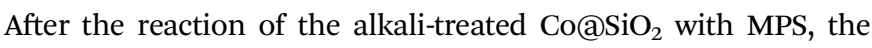
propyl group $\mathrm{H}-\mathrm{C}-\mathrm{H}$ bending absorption band appeared around $1400 \mathrm{~cm}^{-1}$, indicating that the MPS silylation of $\mathrm{Co@SiO}{ }_{2}$ succeeded. The XPS spectrum in Fig. 5 shows that the thiol groups on $\mathrm{Co@SiO} 2$-MPS were oxidized by $7 \mathrm{M}$ aqueous $\mathrm{HNO}_{3}$; the S2p corelevel spectrum indicates that most of the thiol groups $(164 \mathrm{eV})$ were oxidized to sulfonic groups $(169 \mathrm{eV}),{ }^{53}$ and the oxidized product, $\mathrm{Co@SiO}_{2}$-SPS, was formed (the XPS survey spectrum is shown in the ESI, Fig. S2 $\dagger$ ). The amount of sodium ions exchanged with the protons on $\mathrm{Co}_{\mathrm{SiO}_{2}}$-SPS was $0.20 \mathrm{mmol} \mathrm{g}^{-1}$.

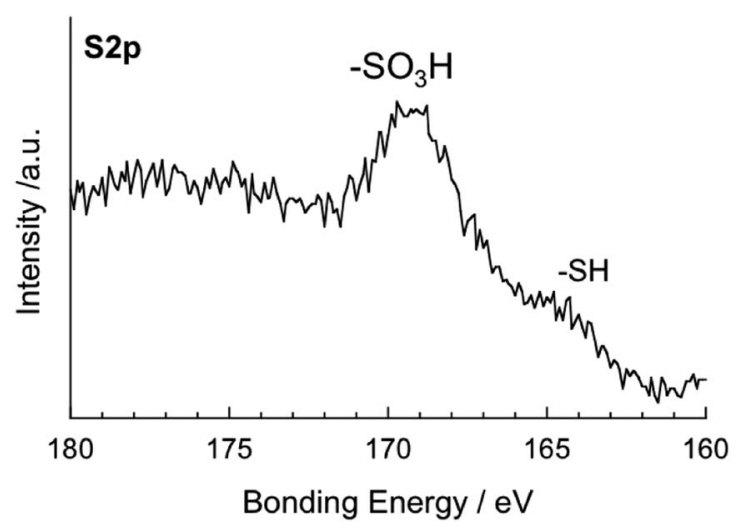

Fig. 5 XPS S2p core-level spectrum of $\mathrm{CoCSiO} 2-$ SPS.
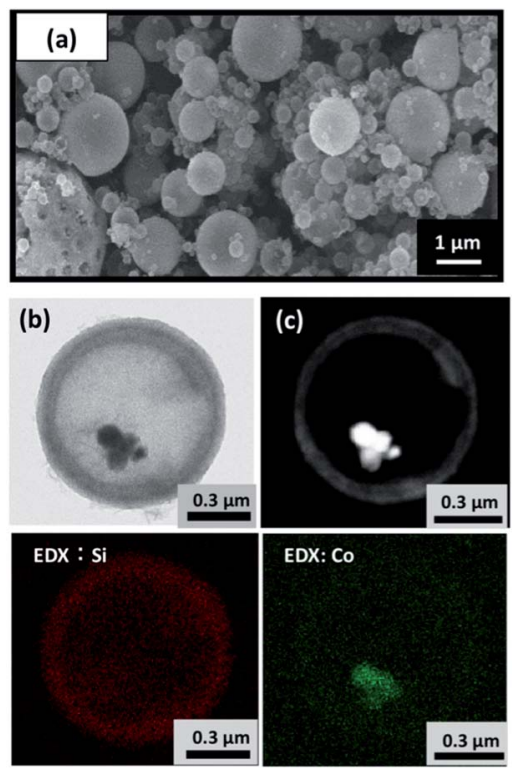

Fig. 6 (a) SEM, (b) TEM, and (c) STEM dark-field images of Co@SiO ${ }_{2}^{-}$ SPS. Elemental mapping images of Si and $\mathrm{Co}$ are shown at the bottom.

The amount slightly decreased during the second run of the treatment with $\mathrm{NaCl}$ and subsequent aqueous $\mathrm{HCl}$ solutions to $0.18 \mathrm{mmol} \mathrm{g}^{-1}$. The occupied area of the trisilylpropylsulfonic acid group was calculated to be $7 \times 10^{-2} \mathrm{~nm}^{-2}$ from the specific surface area derived from the $\mathrm{N}_{2}$ adsorption isotherm for $\mathrm{Co@SiO} 2\left(7 \mathrm{~m}^{2} \mathrm{~g}^{-1}\right)$ and the cation exchange capacity, indicating MPS polymerization and silylation on $\mathrm{Co@SiO}_{2}$.

An SEM image of the $\mathrm{Co@SiO}$-SPS particles is shown in Fig. 6a. They are spherical with an average particle size of $0.7 \mu \mathrm{m}$. The TEM (Fig. 6b) and STEM dark-field images (Fig. 6c)
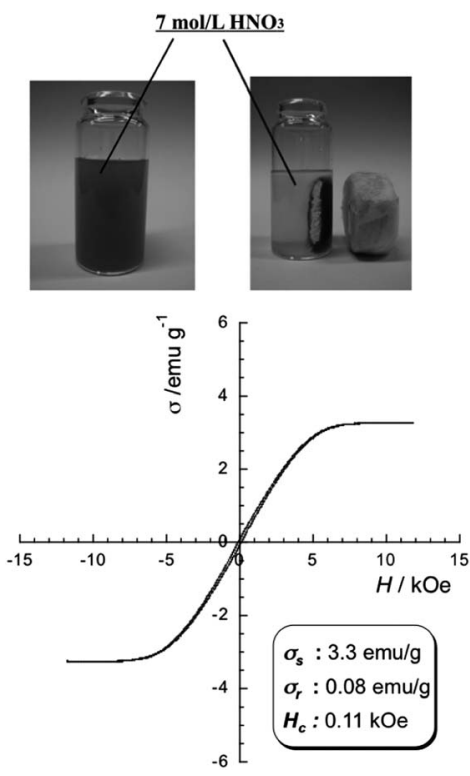

Fig. 7 (Top) Photograph of $\mathrm{CoOSiO}_{2}$-SPS particles attracted to a magnet after they were immersed in $7 \mathrm{M} \mathrm{HNO}_{3}$ to oxidize the thiol group. (Bottom) Magnetization curves of $\mathrm{CoOSiO}_{2}$-SPS measured at room temperature. 
together with EDX elemental maps ( $\mathrm{Si}$ and $\mathrm{Co}$ ) for a typical $\mathrm{Co@SiO}{ }_{2}$-SPS particle show a Co core and a silica shell. The amount of Co encapsulated in the $\mathrm{Co@SiO}{ }_{2}$-SPS particles was determined by ICP to be 6.1 mass\%. Although the amount of Co ions lost during silylation and oxidation was about $20 \%$ of the total $\mathrm{Co}$ in the $\mathrm{Co@SiO} \mathrm{Sir}_{2}$ particles, the magnetism was verified by the fact that the $\mathrm{Co@SiO}{ }_{2}$-SPS particles in $7 \mathrm{M} \mathrm{HNO}_{3}$ were attracted to a magnet (Fig. 7). The magnetization at $12 \mathrm{kOe}$ was calculated to be $3.3 \mathrm{emu}^{-1}$ from the VSM curves in Fig. 7. The small remanence of $\mathrm{Co@SiO}{ }_{2}$-SPS nanoparticles is an advantage for their use as magnetically collectable reusable adsorbents and catalysts.

\section{Adsorption of transition metal ions}

The results of the adsorption of $\mathrm{Zn}$ and $\mathrm{Pb}$ ions from aqueous solutions on Co@SiO ${ }_{2}$-SPS are summarized in Table 1. At pH 5.2 , the amount of zinc ions adsorbed from a lower concentration solution $\left(0.4 \mathrm{mM}\right.$ ) was $0.05 \mathrm{mmol} \mathrm{g}^{-1}$. As shown in Fig. 8, zinc ions rapidly were adsorbed, and the saturation reached within $24 \mathrm{~h}$ under the present experimental conditions. The amount of adsorbed lead ions from the solution of the same concentration was $0.04 \mathrm{mmol} \mathrm{g}^{-1}$, which was slightly smaller than that of zinc ions. When the solution $\mathrm{pH}$ was changed to 2.5 , it slightly decreased the amount of metal ions adsorbed. When the amount of zinc(II) chloride was increased to 10 -fold the cation exchange capacity, the amount of zinc ions adsorbed increased to $0.08 \mathrm{mmol} \mathrm{g}^{-1}$, which is similar to the value of the cation exchange capacity of $\mathrm{Co@SiO}{ }_{2}$-SPS $\left(0.2\right.$ meq. $\left.\mathrm{g}^{-1}\right)$, irrespective of the solution $\mathrm{pH}$. Thus, the adsorption behavior of the transition metal ions for the sulfonic groups on the $\mathrm{Co@SiO}{ }_{2}$-SPS particles can be explained by surface charge and proton competition. We consider that the majority of the incorporated divalent cations are occupying two exchange sites as reported in a sulfonic acid functionalized silica system. ${ }^{54}$ For comparison, the adsorption capacity of some adsorbents (layered silicates, ${ }^{55,56}$ an activated carbon, ${ }^{57}$ a cellulose fiber, ${ }^{11}$ and magnetic particles ${ }^{36,38}$ ) for $\mathrm{Zn}$ (II) and $\mathrm{Pb}$ (II) is listed in Table 2. During the adsorption experiments, the amount of Co leached from the adsorbent was negligible and was less than $1 \%$ of the total Co in the Co@SiO ${ }_{2}$-SPS (less than $5 \times 10^{-4} \mathrm{mmol}$ in $20 \mathrm{~mL}$ of solution).

A transparent supernatant was obtained after the resulting suspension was transferred into a glass bottle with neodymium magnets f for $3 \mathrm{~min}$. The $\mathrm{Co@SiO}$-SPS samples with adsorbed metal ions were regenerated by immersion in $1 \mathrm{M}$ aqueous $\mathrm{HCl}$ with reciprocal shaking. There was no substantial decrease in the amount of metal ions adsorbed onto the regenerated $\mathrm{Co@SiO}$-SPS after the third run, showing that the adsorption was reversible. We also confirmed that the cation-exchange capacity determined by the reaction with $\mathrm{NaCl}$ was maintained after the third run to be 0.17 meq. $\mathrm{g}^{-1}$. The time required for regeneration by immersing in $1 \mathrm{M} \mathrm{HCl}$ was within $2 \mathrm{~h}$. During immersion in $\mathrm{HCl}$ for $6 \mathrm{~h}$, less than $1 \%$ of the total Co in the $\mathrm{Co@SiO}{ }_{2}$-SPS particles was eluted during the regeneration process (Table 1). Acidic regeneration has been examined in an EDTA/chitosan modified magnetic $\mathrm{Fe}_{3} \mathrm{O}_{4}$-silica system. ${ }^{38}$

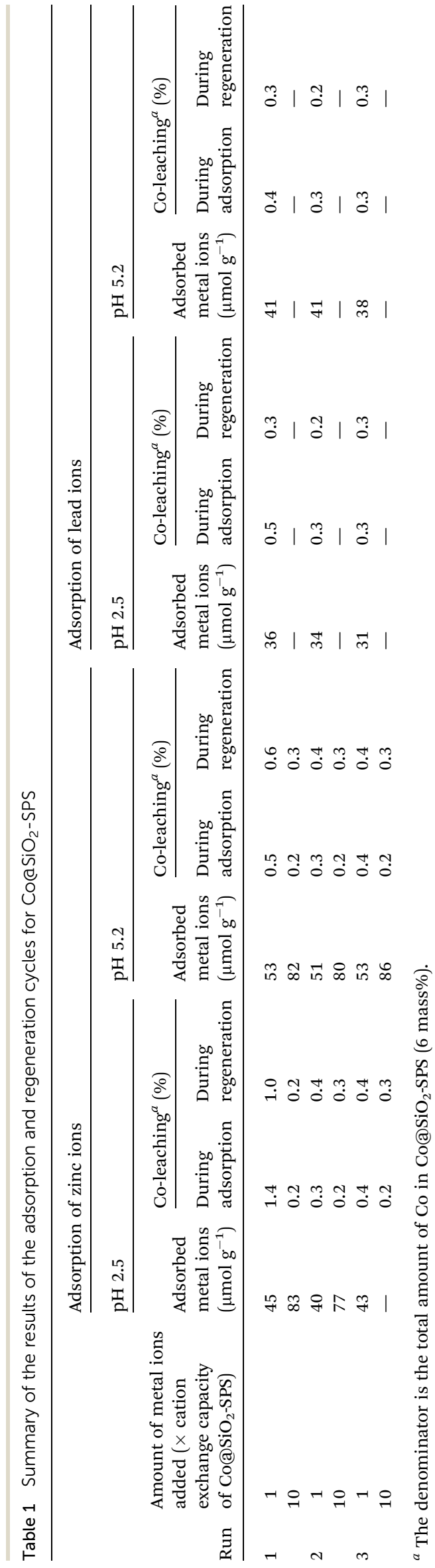


Table 3 Summary of the results of the hydrolysis of ethyl acetate over $\mathrm{CoCSiO} 2$-SPS

Hydrolysis of ethyl acetate

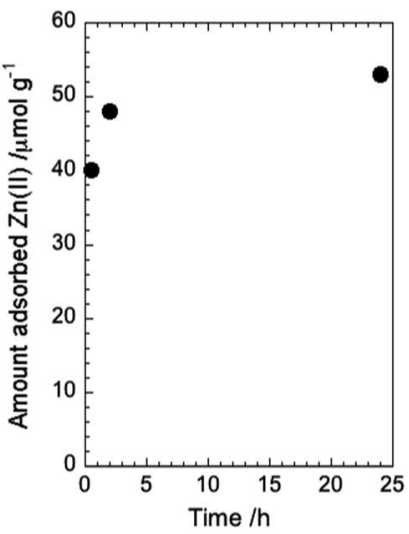

Fig. 8 Time course of adsorption of zinc ions onto $\mathrm{Co} \mathrm{ASiO}_{2}-\mathrm{SPS}$ (the initial concentration of $0.4 \mathrm{mM}$ ).

Table 2 Adsorption capacity of layered silicates, an activated carbon, a cellulose fiber, and magnetic particles for zinc and lead ions

\begin{tabular}{|c|c|c|c|}
\hline Adsorbent & Metal ion & $\begin{array}{l}\text { Adsorption } \\
\text { capacity meq. } \mathrm{g}^{-1}\end{array}$ & Ref. \\
\hline $\begin{array}{l}\mathrm{Fe}_{3} \mathrm{O}_{4} @ E D T A \text { modified } \\
\text { organosilica }\end{array}$ & $\mathrm{Pb}$ (II) & 0.4 & 38 \\
\hline Water soluble $\mathrm{Fe}_{3} \mathrm{O}_{4}$ & $\mathrm{~Pb}(\mathrm{II})$ & 1.0 & 36 \\
\hline Cellulose fiber & $\mathrm{Pb}(\mathrm{II})$ & 0.1 & 11 \\
\hline Activated carbon & $\mathrm{Pb}(\mathrm{II})$ & 0.2 & 57 \\
\hline $\mathrm{Na}-4-m i c a$ & $\mathrm{Zn}(\mathrm{II})$ & 3.0 & 56 \\
\hline Montmorillonite & $\mathrm{Zn}(\mathrm{II})$ & 0.4 & 55 \\
\hline Magadiite & $\mathrm{Zn}(\mathrm{II})$ & 1.0 & 55 \\
\hline $\begin{array}{l}\mathrm{Co@SiO} \text {-SPS } \\
\text { (present study) }\end{array}$ & $\mathrm{Zn}(\mathrm{II}), \mathrm{Pb}(\mathrm{II})$ & 0.2 & - \\
\hline
\end{tabular}

Because of covalently attached sulfonic groups in our system, the sorption sites were regenerated by an acidic solution without degradation. Thus, the $\mathrm{Co@SiO}_{2}$-SPS nanoparticles are suitable as a magnetically collectable and reusable adsorbent for transition metal ions in water.

\section{Hydrolysis of ethyl acetate in aqueous solution}

Table 3 lists the catalytic activity of $\mathrm{Co@SiO}_{2}$-SPS for the hydrolysis of ethyl acetate. The activity was estimated from the amount of acetic acid produced after $2 \mathrm{~h}$, and was normalized by the time and the amount of immobilized sulfonic groups.

\begin{tabular}{llll}
\hline \multicolumn{4}{c}{ Hydrolysis of ethyl acetate } \\
\cline { 2 - 4 } Runs & $\begin{array}{l}\text { Conversion } \\
(\%)\end{array}$ & $\begin{array}{l}\text { Rate per unit of acid } \\
\left(10^{2} \mathrm{mmol}\right. \\
\left.(\text { acid-mol })^{-1} \mathrm{~min}^{-1}\right)\end{array}$ & $\begin{array}{l}\text { Cation exchange } \\
\text { capacity } \\
\left(\mathrm{mmol} \mathrm{g}^{-1}\right)\end{array}$ \\
\hline 1 & 1.0 & 0.8 & 0.19 \\
2 & 2.0 & 2.2 & 0.16 \\
3 & 1.8 & 2.1 & 0.18
\end{tabular}

The activity per unit acid site was comparable to the values reported for $\mathrm{H}_{2} \mathrm{SO}_{4}$ and other solid acids (e.g. H-ZSM-5, Nafion, $\left.\mathrm{Cs}_{2.5} \mathrm{H}_{0.5} \mathrm{PW}_{12} \mathrm{O}_{40}\right) .{ }^{58-60}$ The reactions became stable after a second run, suggesting that $\mathrm{Co@SiO}{ }_{2}$-SPS nanoparticles can be reused without any significant loss of activity. The negligible

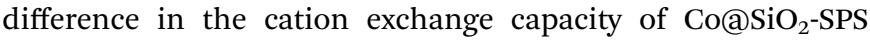
suggests that the active catalytic active sites were not degraded by repeated reactions, and that there was no significant erosion of Co from the catalyst support which poisoned the active sites.

Ether hydrolysis ${ }^{27}$ and Mannich reactions ${ }^{40}$ in water over $\mathrm{Cs}_{2.5} \mathrm{H}_{0.5} \mathrm{PW}_{12} \mathrm{O}_{40}$ mounted amine-modified silica containing magnetic iron oxides have been reported, and resulted in negligible leaching of the iron ${ }^{27}$ and the cesium acidic salt. ${ }^{39}$ Gill et al. ${ }^{61}$ and Takagaki et al. ${ }^{62}$ reported acid-catalytic reactions over $\mathrm{CoFe}_{2} \mathrm{O}_{4} @$ sulfonic acid-modified organosilica core-shell particles in organic solvents and in water, respectively. $\mathrm{Co@SiO}{ }_{2}$-SPS nanoparticles are the first example of a magnetically collectable reusable solid acid, with cation exchange ability, which does not undergo substantial erosion of the magnetic particles.

\section{Conclusions}

We have successfully produced chemically stable magnetic particles which remove $\mathrm{Zn}$ (II) and $\mathrm{Pb}$ (II) ions and function as a solid acid catalyst in water. Rattle-type $\mathrm{Co@SiO} \mathrm{Si}_{2}$ particles were prepared and trisilylpropylsulfonic acid was grafted onto the silica surface. Because of the dense silica shell, the adsorbent could be regenerated without losing the magnetism, even after treatment with $1 \mathrm{M} \mathrm{HCl}$. The catalytic activity for the hydrolysis of ethyl acetate in water was not decreased substantially, even after activation by $1 \mathrm{M} \mathrm{HCl}$. In addition, the multi-functional magnetic particles were readily recovered with neodymium magnets. The reusability and the retention of magnetism are important for the practical use of magnetically collectable adsorbents for heavy-metal ions and catalysts.

\section{Acknowledgements}

One of the authors (T.O.) thanks JSPS (Grant-in-Aid for Scientific Research, \# 23655143), JST (A-STEP), Nippon Sheet Glass Foundation for Materials Science and Engineering, and Shinshu University (Funding Program for Green Innovation). XPS measurement was kindly assisted by Prof. Katsuya Teshima, $\mathrm{Mr}$ Yusuke Mizuno, and Mr Daiki Kojima.

\section{Notes and references}

1 V. Sokolova and M. Epple, Angew. Chem., Int. Ed., 2008, 47, 1382.

2 A. H. Latham and M. E. Williams, Acc. Chem. Res., 2008, 41, 411.

3 Y. W. Jun, J. W. Seo and A. Cheon, Acc. Chem. Res., 2008, 41, 179.

4 U. Jeong, X. Teng, Y. Wang, H. Yang and Y. Xia, Adv. Mater., 2007, 19, 33.

5 M. Mahmoudi, S. Sant, B. Wang, S. Laurent and T. Sen, Adv. Drug Delivery Rev., 2011, 63, 24. 
6 A.-H. Lu, E. L. Salabas and F. Schüth, Angew. Chem., Int. Ed., 2007, 46, 1222.

7 B. Luo, X.-J. Song, F. Zhang, A. Xia, W.-L. Yang, J.-H. Hu and C.-C. Wang, Langmuir, 2010, 26, 1674.

8 K. Katagiri, M. Nakamura and K. Koumoto, ACS Appl. Mater. Interfaces, 2010, 2, 768.

9 V. Salgueiriño-Maceira, M. A. Correa-Duarte, M. Spasova, L. M. Liz-Marzán and M. Farle, Adv. Funct. Mater., 2006, 16, 509.

10 H. Ma, B. S. Hsiao and B. Chu, ACS Macro Lett., 2012, 1, 213.

11 A. Kardam, K. R. Raj, S. Srivastava and M. M. Srivastava, Clean Technol. Environ. Policy, DOI: 10.1007/s10098-0130634-2, in press.

12 S. K. Das, M. M. R. Khan, T. Paradhaman, F. Laffir, A. K. Guha, G. Sekaran and A. B. Mandal, Nanoscale, 2013, $5,5549$.

13 T. Okada, Y. Ide and M. Ogawa, Chem. - Asian J., 2012, 7, 1980.

14 Y. González-Alfaro, P. Aranda, F. M. Fernandes, B. Wicklein, M. Darder and E. Ruiz-Hitzky, Adv. Mater., 2011, 23, 5224.

15 F. Caruso, Adv. Mater., 2001, 13, 11.

16 X. W. Lou, L. A. Archer and Z. Yang, Adv. Mater., 2008, 20, 3987.

17 V. Salgueiriño-Maceira and M. A. Correa-Duarte, J. Mater. Chem., 2006, 16, 3593.

18 Y. Kobayashi, M. Horie, M. Konno, B. Rodríguez-González and L. M. Liz-Marzán, J. Phys. Chem. B, 2003, 107, 7420.

19 Y. Leng, K. Sato, Y. Shi, J.-G. Li, T. Ishigaki, T. Yoshida and H. Kamiya, J. Phys. Chem. C, 2009, 113, 16681.

20 Y. D. Liu, H. J. Choi and S.-B. Choi, Colloids Surf., A, 2012, 403, 133.

21 I. Y. Goon, L. M. H. Lai, M. Lim, P. Munroe, J. J. Gooding and R. Amal, Chem. Mater., 2009, 21, 673.

22 A.-H. Lu, W. C. Li, N. Matoussevitch, B. Spliethoff, H. Bonnemann and F. Schüth, Chem. Commun., 2005, 98.

23 A.-H. Lu, W. Schmidt, N. Matoussevitch, H. Bonnemann, B. Spliethoff, B. Tesche, E. Bill, W. Kiefer and F. Schüth, Angew. Chem., Int. Ed., 2004, 43, 4303.

24 I.-S. Park, M. Choi, T.-W. Kim and R. Ryoo, J. Mater. Chem., 2006, 16, 3409.

25 M. Aslam, S. Li and V. P. Dravid, J. Am. Ceram. Soc., 2007, 90, 950.

26 Q. Liu, H. Xu, J. A. Finch and R. Egerton, Chem. Mater., 1998, 10, 3936.

27 T. Goto, Y. Sakamoto and Y. Kamiya, Chem. Lett., 2009, 736.

28 J. Lee, Y. Lee, J. K. Youn, H. B. Na, T. Yu, H. Kim, S.-M. Lee, Y.-M. Koo, J. H. Kwak, H. G. Park, H. N. Chang, M. Hwang, J.-G. Park, J. Kim and T. Hyeon, Small, 2008, 4, 143.

29 O. Hakami, Y. Zhang and C. J. Banks, Water Res., 2012, 46, 3913.

30 H. Bagheri, A. Afkhami, M. Saber-Tehrani and H. Khoshsafar, Talanta, 2012, 97, 87.

31 K. M. Yeo, S. I. Lee, Y. T. Lee, Y. K. Chung and I. S. Lee, Chem. Lett., 2008, 116.

32 Y. Ren, Z. Wei and M. Zhang, J. Hazard. Mater., 2008, 158, 14.

33 Y.-C. Chang and D.-H. Chen, J. Colloid Interface Sci., 2005, 283, 446.
34 V. Polshettiwar and R. S. Varma, Chem. - Eur. J., 2009, 15, 1582.

35 J.-F. Liu, Z.-S. Zhao and G.-B. Jiang, Environ. Sci. Technol., 2008, 42, 6949.

36 L. Wang, J. Li, Q. Jiang and L. Zhao, Dalton Trans., 2012, 4544.

37 C. T. Yavuz, J. T. Mayo, W. W. Yu, A. Prakash, J. C. Falkner, S. Yean, L. Cong, H. J. Shipley, A. Kan, M. Tomson, D. Natelson and W. L. Colvin, Science, 2006, 314, 964.

38 Y. Ren, H. A. Abbood, F. He, H. Peng and K. Huang, Chem. Eng. J., 2013, 226, 300.

39 B. Hai, J. Wu, Z. Chen, J. D. Protasiewicz and D. A. Scherson, Langmuir, 2005, 21, 3104.

40 E. Rafiee and S. Eavani, Green Chem., 2011, 13, 2116.

41 S. Xuan, W. Jiang, X. Gong, Y. Hu and Z. Chen, J. Phys. Chem. $C, 2009,113,553$.

42 Y.-T. Zhou, H.-L. Nie, C. Branford-White, Z.-Y. He and L.-H. Zhu, J. Colloid Interface Sci., 2009, 330, 29.

43 Y.-T. Zhou, C. Branford-White, H.-L. Nie and L.-H. Zhu, Colloids Surf., B, 2009, 74, 244.

44 M. V. Barmatova, I. D. Ivanchikova, O. A. Kholdeeva, A. N. Shmakov, V. I. Zaikovskii and M. S. Mel'gunov, J. Mater. Chem., 2009, 19, 7332.

$45 \mathrm{~J} . \mathrm{Hu}, \mathrm{G}$. Chen and I. M. C. Lo, Water Res., 2005, 39, 4528.

46 K. Mori, N. Yoshioka, Y. Kondo, T. Takeuchi and H. Yamashita, Green Chem., 2009, 11, 1337.

47 S. Mishima, M. Kawamura, S. Matsukawa and T. Nakajima, Chem. Lett., 2002, 1092.

48 T. Okada, S. Mishima and S. Yoshihara, Chem. Lett., 2009, 32.

49 T. Okada, N. Watanabe, T. Haeiwa, T. Sakai and S. Mishima, Chem. Lett., 2010, 106.

50 T. Okada, Y. González-Alfaro, A. Espinosa, N. Watanabe, T. Haeiwa, M. Sonehara, S. Mishima, T. Sato, A. MuñozNoval, P. Aranda, M. Garcia-Hernández and E. Ruiz-Hitzky, J. Appl. Phys., 2013, 114, 124304.

51 Y. Ide, G. Ozaki and M. Ogawa, Langmuir, 2009, 25, 5276.

52 R. Salmimies, M. Mannila, J. Kallas and A. Häkkinen, Clays Clay Miner., 2011, 59, 136.

53 J. G. C. Shen, R. G. Herman and K. Kiler, J. Phys. Chem. B, 2002, 106, 9975.

54 V. Ganesan and A. Walcarius, Langmuir, 2004, 20, 3632.

55 Y. Ide, N. Ochi and M. Ogawa, Angew. Chem., Int. Ed., 2011, 50, 654 .

56 T. Kodama and S. Komarneni, J. Mater. Chem., 1999, 9, 533. 57 T. M. Alslaibi, I. Abustan, M. A. Ahmad and A. A. Foul, Environ. Prog. Sustainable Energy, DOI: 10.1002/ep.11877, in press.

58 M. Kimura, T. Nakato and T. Okuhara, Appl. Catal., A, 1997, $165,227$.

59 K. Inumaru, T. Ishihara, Y. Kamiya and T. Okuhara, Angew. Chem., Int. Ed., 2007, 46, 7625.

60 T. Okada, K. Miyamoto, T. Sakai and S. Mishima, ACS Catal., 2014, 4, 73.

61 C. S. Gill, B. A. Price and C. W. Jones, J. Catal., 2007, 251, 145. 62 A. Takagaki, M. Nishimura, S. Nishimura and K. Ebitani, Chem. Lett., 2011, 1195. 